\title{
Highest Diploid Number Among Gymnotiformes: First Cytogenetic Insights into Rhabdolichops (Sternopygidae)
}

\author{
Pablo Suárez, ${ }^{1,2, *}$ Inaê Cristina Guerreiro Pinto Barroso,, ${ }^{1, *}$ Danillo dos Santos Silva, ${ }^{3}$ \\ Susana S.R. Milhomem, ${ }^{4}$ Diogo Cavalcanti Cabral-de-Mello, ${ }^{5}$ Cesar Martins, \\ Julio Cesar Pieczarka, and Cleusa Yoshiko Nagamachi ${ }^{1}$
}

\begin{abstract}
We report the first comparative cytogenetic analysis of two species from electrogenic fish of genus Rhabdolichops (Sternopygidae, Gymnotiformes): Rhabdolichops troscheli and Rhabdolichops of eastwardi. R. troscheli has $2 \mathrm{n}=54$ (fundamental number $[\mathrm{FN}]=66$ ), whereas $R$. cf. eastwardi has $2 \mathrm{n}=74(\mathrm{FN}=78)$. C-banding revealed centromeric constitutive heterochromatin in both species. Ag-NORs mapped on pair 6 in $R$. troscheli and pair 30 in $R$. cf eastwardi. Fluorescense in situ hybridization with 18S rDNA probes confirmed the Ag-NOR staining results and revealed additional (presumably silent) ribosomal genes on pairs 12, 13, 21, 23, 26, and 27 in $R$. cf eastwardi. 5S rDNA was found on the centromeres of pair 7 in both species. Telomeric probes showed only distal locations. Dispersed signal patterns were obtained using probes for retrotransposons Rex 1 and Rex3. Histone $\mathrm{H} 1$ and $\mathrm{H} 3$ genes were found together on pair 6 in $R$. cf eastwardi. The high diploid number found in Rhabdolichops suggests that chromosome fission may have contributed to its chromosomal evolution, phylogenetic relationship of the Sternopygidae suggests that this increase in diploid number could be a synapomorphic characteristic of genus Rhabdolichops. Although both species are phylogenetically close related, their karyotype structure has undergone divergent evolutionary directions. All in all, our results strongly suggest that $R$. cf eastwardi experencied recent intense genome reorganization.
\end{abstract}

Keywords: electric fish, chromosomes, biodiversity, Amazon rainforest, karyotypic diversity

\section{Introduction}

$\mathbf{T}$ HE ELECTROGENIC FISH of the genus Rhabdolichops inhabit the lowlands of South America, and are found in the basins of the Amazon and Orinoco and the minor basins of the Guianas. ${ }^{1}$ Rhabdolichops, Archolaemus, Distocyclus, Eigenmannia, Japigny, and Sternopygus together comprise the monophyletic family, Sternopygidae, whose members are widely distributed in Neotropical regions. ${ }^{1,2}$ Ten species of Rhabdolichops are currently recognized; most of them feed on zooplankton, and they are commonly found in the benthic regions of deep rivers. ${ }^{3-5}$

Phylogenetic analyses revealed Sternopygidae to be a monophyletic group that comprises two clades with a sister taxon relationship. ${ }^{2}$ The Sternopygus species form one clade, while the other clade, which is known as the Eigenmanninae subfamily, includes all remaining genera of this family. Rhabdolichops appears in a basal phylogenetic position among the Eigenmanninae genera, but the monophyly of these genera is called into question by the positioning of Rhabdolichops lundbergi and Rhabdolichops nigricans, which are more closely related to Eigenmannia than to the other Rhabdolichops species. ${ }^{2}$

Cytogenetics studies among Gymnotiformes are still in early stages. The species of genera Gymnotus and Eigenmannia have been the most widely studied to date (for review see Refs. ${ }^{6,7}$ ). The Gymnotiformes already studied show great karyotypic diversity, with diploid numbers ranging from

\footnotetext{
${ }^{1}$ Laboratório de Citogenética, Centro de Estudos Avançados da Biodiversidade, Instituto de Ciências Biológicas, Universidade Federal do Pará, Belém, Brazil.

${ }^{2}$ Instituto de Biología Subtropical, CONICET-UNaM, Puerto Iguazú, Argentina.

${ }^{3}$ Universidade do Estado do Pará, Marabá, Brazil.

${ }_{5}^{4}$ Instituto Federal de Educação, Ciência e Tecnologia de Goiás, Valparaiso de Goiás, Brazil.

${ }^{5}$ Instituto de Biociências, Universidade Estadual Paulista Julio de Mesquita Filho, Rio Claro, Brazil.

${ }^{6}$ Instituto de Biociências, Universidade Estadual Paulista Julio de Mesquita Filho, Botucatu, Brazil.

*These two authors contributed equally to this work.
} 
$2 \mathrm{n}=22 / 24$ in Apteronotus albifrons ${ }^{8}$ to $2 \mathrm{n}=54$ in Gymnotus inaequilabiatus, ${ }^{9}$ Gymnotus carapo, ${ }^{9}$ Gymnotus mamiraua, ${ }^{10}$ and Gymnotus paraguensis. ${ }^{11}$

In Sternopygidae, cytogenetic results have been published only for Sternopygus macrurus, which has a conserved $2 n=46$ karyotype, ${ }^{12,13}$ and several chromosomally diversified species of Eigenmannia, which reportedly have $2 \mathrm{n}=28,32,32 / 31$, and 38 . $^{7,14,15}$ Sex-chromosome systems have been found in some species of Eigenmannia; they range from female heterogametic systems (ZZ/ZW) to single or multiple male heterogametic systems (XX/XY or $\left.\mathrm{X}_{1} \mathrm{X}_{1} \mathrm{X}_{2} \mathrm{X}_{2} / \mathrm{X}_{1} \mathrm{X}_{2} \mathrm{Y}\right)$. $^{7,12,15-17}$

The major ribosomal genes (the $18 \mathrm{~S}$ or $45 \mathrm{~S}$ rDNAs) and that encoding the 5S rDNA have been mapped in some $E i$ genmannia species, with the latter exhibiting multiple centromeric locations in most of the tested species. ${ }^{14}$ Interstitial telomere sequences (ITSs) were found in a species of $\mathrm{Ei}$ genmannia with a low diploid number. ${ }^{14}$ To date, no cytogenetic information has been published for Archolaemus, Distocyclus, Japigny, or Rhabdolichops.

In this study, we present the first conventional and molecular cytogenetic analysis of two species of Rhabdolichops troscheli and Rhabdolichops cf eastwardi from the eastern region of Amazon rainforest.

\section{Materials and Methods}

\section{Samples}

Four specimens of $R$. cf eastwardi (P-153/P-1540-1) and one $R$. troscheli (P-1903-4) were collected from two localities in the eastern Amazon rainforest (Fig. 1): one $R$. cf eastwardi and the $R$. troscheli in the Abaetetuba municipality (Caripetuba River: $\left.01^{\circ} 37^{\prime} 23.49^{\prime \prime} \mathrm{S} / 048^{\circ} 55^{\prime} 33^{\prime \prime} \mathrm{W}\right)$ and three $R$. cf eastwardi in the Barcarena Municipality (Arienga River: $1^{\circ} 36^{\prime} 28.40^{\prime \prime S} /$ $\left.48^{\circ} 48^{\prime} 16.70^{\prime \prime} \mathrm{W}\right)$. Samples were collected with seine nets in agreement with Brazilian environmental protection legislation, under license 020/2005 (ICMBio Registration: 207419).

Specimens were kept alive with portable aeration and transported to the laboratory. They were then anesthetized with benzocaine hydrochloride solution and euthanized. Representative samples have been deposited in the Ichthyology Collections of the Centro de Estudos Avançados da Biodiversidade (CEABIO) of Universidade Federal do Pará (Belém, Brazil).

\section{Chromosome preparations}

Mitotic chromosomes were obtained from cephalic kidney cell suspensions. ${ }^{18}$ Conventional karyotyping was performed

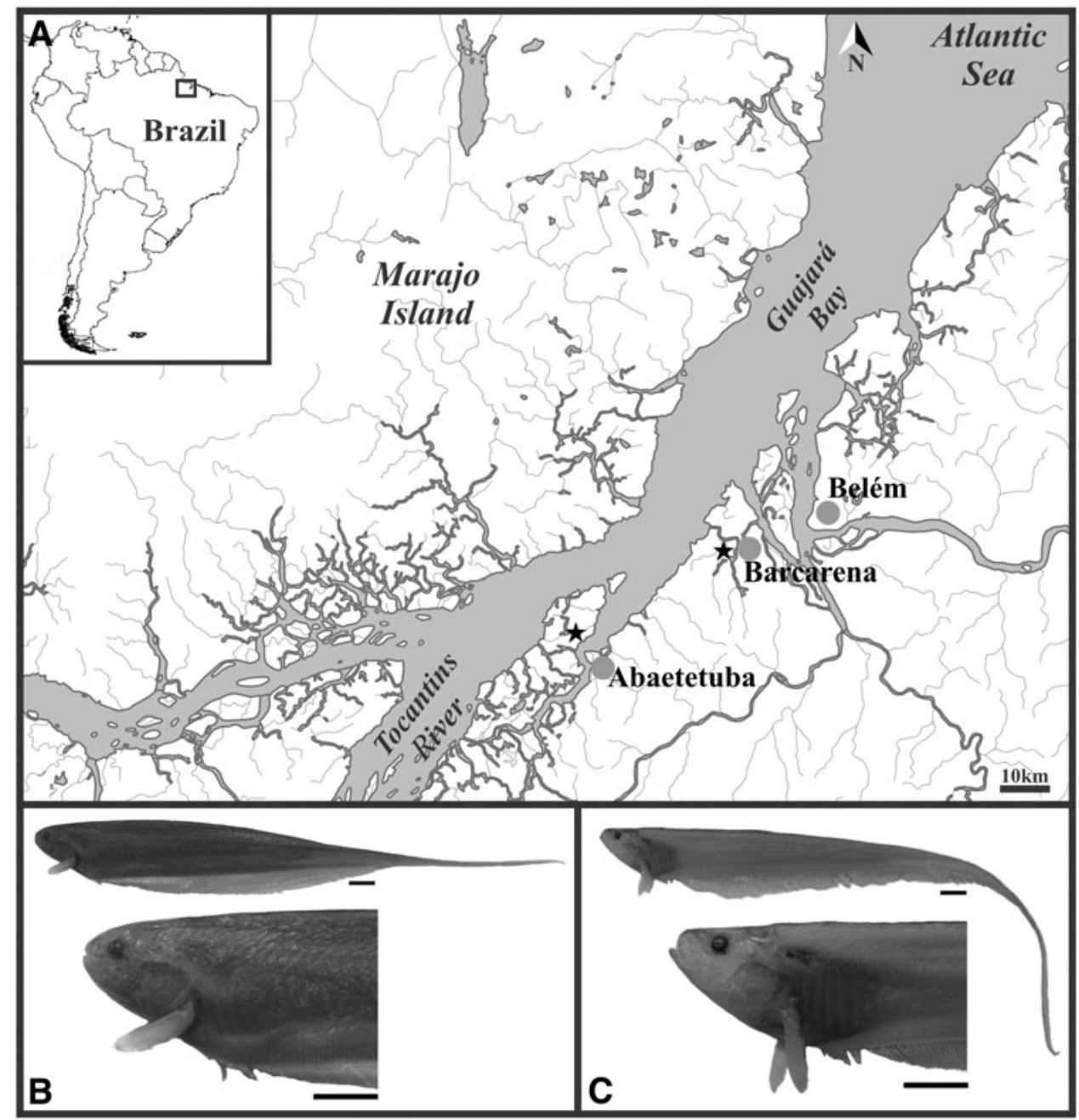

FIG. 1. Geographic locations (stars) of the sampling sites (A), and specimens of Rhabdolichops cf eastwardi (B) and Rhabdolichops troscheli $(\mathbf{C})$. Bar $(\mathbf{B}, \mathbf{C})=1 \mathrm{~cm}$. 
with Giemsa staining. Constitutive heterochromatin $(\mathrm{CH})$ was characterized by C-banding. ${ }^{19}$ Impregnation of NOR (nucleolar organizer region) with silver nitrate (Ag-NOR staining) was used to detect the nucleolar activity of major ribosomal genes. ${ }^{20} \mathrm{DAPI} \mathrm{CMA}_{3}$ (4',6-diamidino-2phenylindole and Chromomycin A3) fluorochrome staining was used to identify AT- and GC-rich regions. ${ }^{21}$

For molecular characterizations of chromosomes, we performed fluorescense in situ hybridization (FISH) ${ }^{22}$ with probes for $18 \mathrm{~S}$ rDNA, 5S rDNA, telomeric sequences (TTAGGG)n, histone $\mathrm{H} 1$, histone $\mathrm{H} 3$, and the retrotransposable elements Rex 1 and Rex3. The probes were labeled with digoxigenin-11dUTP or biotin-16-dUTP and detected using avidin labeled with $\mathrm{Cy} 3$ (cyanine 3) or FITC (fluorescein isothiocyanate) or antidigoxigenin (labeled with FITC). Images were captured using a Nikon H550S fluorescent photomicroscope equipped with the Nis-Elements software. Karyotypes were built by digital handling with Adobe Photoshop CS5. Chromosomes were classified as described ${ }^{23}$ : they were distributed according to their arm ratios as submetacentric or subtelocentric/ acrocentric chromosomes and arranged by decreasing size in each group.

\section{Probe preparation}

Cell suspensions of $R$. cf eastwardi and R. troscheli were used for DNA purification with the DNAzol reagent (Invitrogen). The major ribosomal $18 \mathrm{~S}$ rDNA genes were amplified $^{24}$ and labeled with digoxigenin-11-dUTP using the DIG-Nick Translation Mix (Roche). The coding region of the minor ribosomal 5S rDNA was amplified by polymerase chain reaction (PCR) using own design primers $5 \mathrm{rF}$ (5'-GCC ACA CCA CCC TGA ACA C-3') and 5rR (5'GCC TAC GAC ACC TGG TAT TC-3'). PCR was performed in a final volume of $25 \mu \mathrm{L}$ containing $100 \mathrm{ng}$ of genomic DNA, $1 \times$ NH4-based polymerase reaction buffer, $200 \mu \mathrm{M}$ of each dNTP (or for labeling PCR experiments, $200 \mu \mathrm{M}$ dATP, $200 \mu \mathrm{M}$ dCTP, $200 \mu \mathrm{M}$ dGTP, $140 \mu \mathrm{M}$ dTTP, and $60 \mu \mathrm{M}$ biotin-16-dUTP), $0.4 \mu \mathrm{M}$ of each primer,
$1.5 \mathrm{mM}$ of $\mathrm{MgCl}_{2}$, and $2 \mathrm{U}$ of BIOTAQ ${ }^{\mathrm{TM}}$ DNA Polymerase (BIOLINE).

The cycling conditions were as follows: $5 \mathrm{~min}$ at $95^{\circ} \mathrm{C} ; 30$ cycles of $1 \mathrm{~min}$ at $95^{\circ} \mathrm{C}, 30 \mathrm{~s}$ at $50^{\circ} \mathrm{C}$, and $45 \mathrm{~s}$ at $72^{\circ} \mathrm{C}$; and a final extension step at $72^{\circ} \mathrm{C}$ for $5 \mathrm{~min}$. A probe for the general vertebrate telomeric sequence (TTAGGG)n was generated and PCR labeled ${ }^{25}$ using primers (TTAGGG) $)_{5}$ and (CCCTAA $)_{5}$. The coding domains of the reverse transcriptase genes of the retrotransposons, $\operatorname{Rex} 1$ and $\operatorname{Rex} 3$, were PCR amplified with primers RTX1-F1 (5'-TTC TCC AGT GCC TTC AAC ACC-3') and RTX1-R3 (5'-TCC CTC AGC AGA AAG AGT CTG CTC-3') for Rex $1,{ }^{26}$ and RTX3-F3 (5'-CGG TGA YAA AGG GCA GCC CTG-3') and RTX3-R3 (5'TGG CAG ACN GGG GTG GTG GT-3') for Rex3. ${ }^{27}$

Histone $\mathrm{H} 1$ was amplified by PCR using own design primers H1f (5'-AGA RGA GCG GCG TGT-3') and H1r (5'-CYT CTT CRC CTT CYT KG-3'), and H3 were amplified with degenerate primers H3F1 (5'GGC NMG NAC NAA RCA RAC) and H3R1 (5'TGD ATR TCY TTN GGC ATD AT), ${ }^{28}$ respectively. All PCR products were confirmed on $1 \%$ agarose gels and quantified using an Epoch ${ }^{\mathrm{TM}}$ Multi-Volume Spectrophotometer System (Bio Tek).

\section{Results}

\section{Rhabdolichops troscheli}

All the analyzed specimens exhibited karyotypes with a diploid number $(2 \mathrm{n})$ of 54 chromosomes, a karyotypic formula (KF) of $12 \mathrm{sm}$ (submetacentrics) and 42 st/a (subtelocentrics/acrocentrics), and no sex chromosome system with a fundamental number $(\mathrm{FN})=66$ (Fig. 2A). Ag-NOR staining was found pericentromerically on the short arm of pair 6 (Fig. 2A, square), which was consistent with the results of our in situ hybridization experiments with the $18 \mathrm{~S}$ rDNA probes (Fig. 3A). The C-banding pattern corresponded to mainly centromeric $\mathrm{CH}$ (Fig. 2B). The DAPI/CMA 3 pattern indicated the presence of AT-rich $\mathrm{CH}$ (Fig. 3A) and CG-rich NORs (Fig. 3B). FISH with 5S rDNA probes showed a centromeric signal on pair 7 (Fig. 3A, square).
FIG. 2. $R$. troscheli. (A) Giemsa-stained karyotype and the Ag-NOR signal (square) on chromosome pair 6. (B) Karyotype showing the Cbanding pattern. $\mathrm{Bar}=5 \mu \mathrm{m}$.

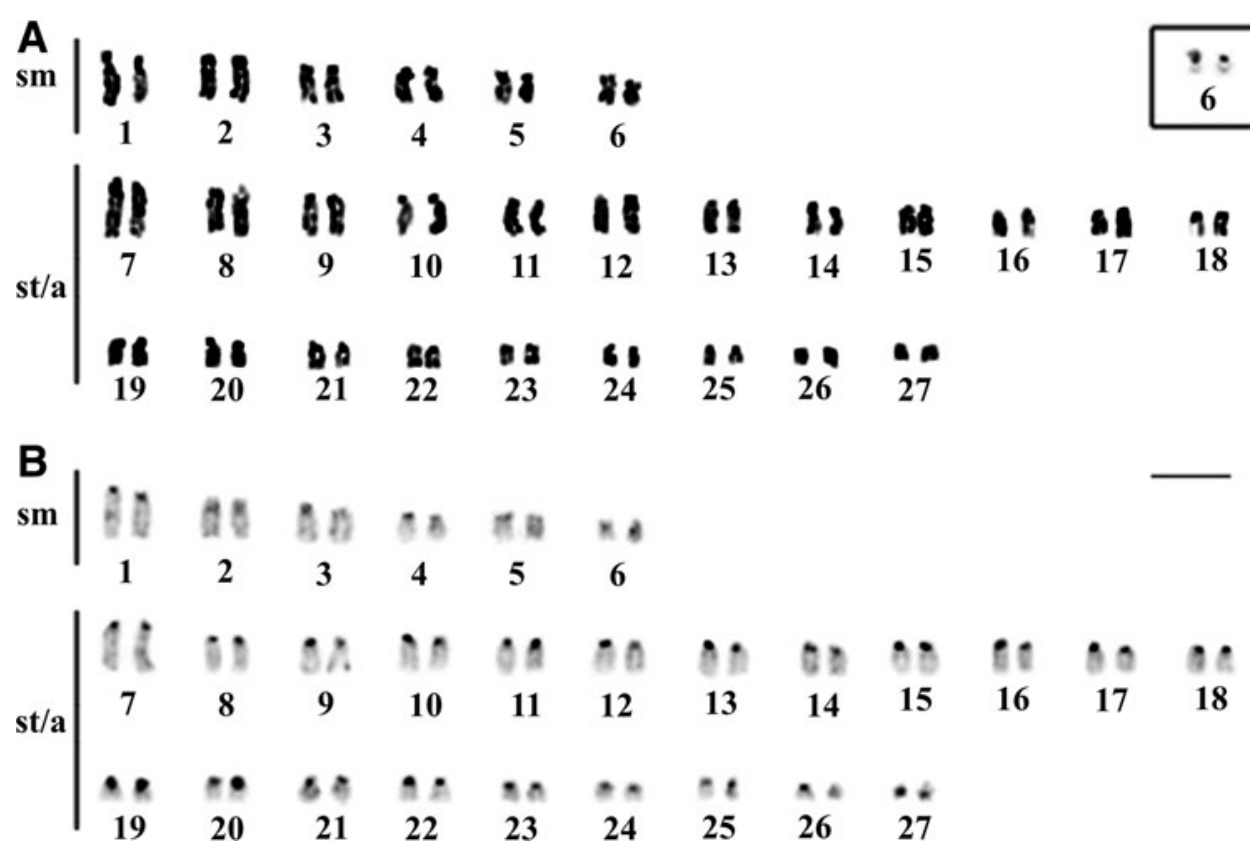



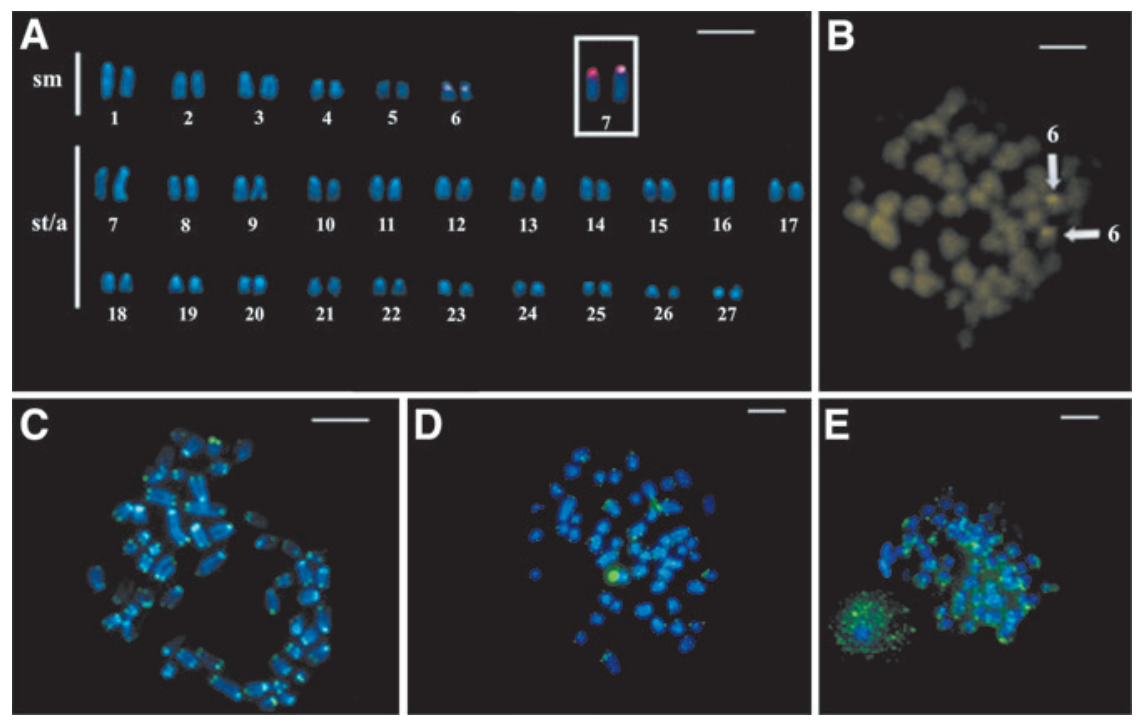

FIG. 3. $R$. troscheli. (A) DAPIcounterstained karyotypes showing FISH with 18S rDNA probes (red mark on pair 6) and 5S rDNA (square on pair 7). (B) $\mathrm{CMA}_{3}$-stained metaphase chromosomes exhibiting pericentric positivity on the short arm of pair 6 (white arrows). (C) FISH with telomeric probes shows signals only at the chromosome tips. (D) FISH with Rex 1 probe shows a scattered signal pattern. (E) FISH with Rex3 probe shows a scattered signal pattern. Bar $=$ $5 \mu \mathrm{m}$. FISH, fluorescense in situ hybridization.
The probe (TTAGGG)n detected the terminal sites in all chromosome complements with different signal intensities, and no ITSs were detected (Fig. 3C). Finally, FISH with the Rexl and Rex3 probes revealed the presence of these repetitive elements on some heterochromatic regions (Fig. 3D and E, respectively).

\section{Rhabdolichops of eastwardi}

All specimens of this species exhibited karyotypes of $2 n=74$ chromosomes, a KF of $4 \mathrm{sm}$ and $70 \mathrm{st} / \mathrm{a}(\mathrm{FN}=78)$
(Fig. 4A), and no sex chromosome system. Ag-NOR positivity was detected distally on pair 30 (Fig. 4A, square). The $\mathrm{C}$-banding pattern indicated that $\mathrm{CH}$ was present at almost all centromeric regions (Fig. 4B). Fluorochrome banding indicated that most of the centromeric $\mathrm{CH}$ corresponded to ATrich (DAPI-positive) regions (Fig. 5A), although there were three distal $\mathrm{CG}$-rich $\left(\mathrm{CMA}_{3}\right.$-positive) regions, which were observed on pairs 23, 24, and 30 (Fig. 5B). In situ hybridization experiments revealed that an $18 \mathrm{~S}$ rDNA signal coincided with the distal Ag-NOR signal on pair 30 and also with the telomeres of pairs 11, 12, 13, 21, 23, 24, 26, and 27
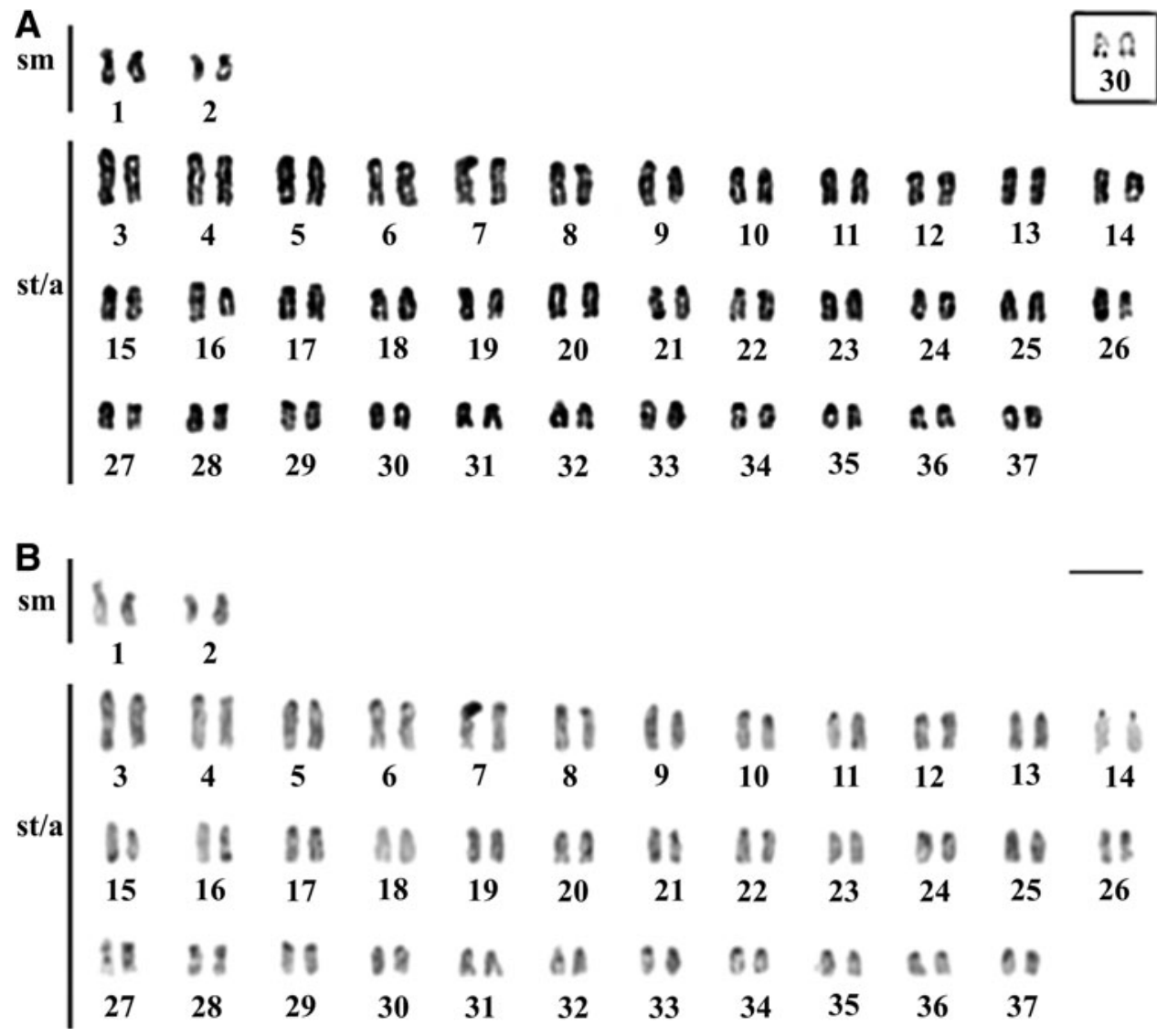

FIG. 4. Karyotype of $R$. cf eastwardi. (A) Giemsa-stained karyotype and the Ag-NOR staining (square) on chromosome pair 30. (B) C-banding pattern. Bar $=5 \mu \mathrm{m}$. 
FIG. 5. $R$. cf eastwardi. (A) DAPI-counterstained karyotypes showing FISH with $18 \mathrm{~S}$ rDNA probes (red marks on pairs 11-13, 21, 23-24, 26-27, and 30) and the 5S rDNA (square on pair 7). (B) $\mathrm{CMA}_{3}-$ stained metaphase chromosomes exhibiting positive bands on pairs 23-24, and 30 (white arrows). (C) FISH with telomeric probes shows signals only at the chromosome tips. (D) FISH with histone $\mathrm{H} 1$ probe. (E) FISH with histone H3 probe. (F) FISH with Rex 1 probe shows a scattered signal pattern. (G) FISH with Rex3 probe shows a scattered signal pattern. $\mathrm{Bar}=5 \mu \mathrm{m}$.
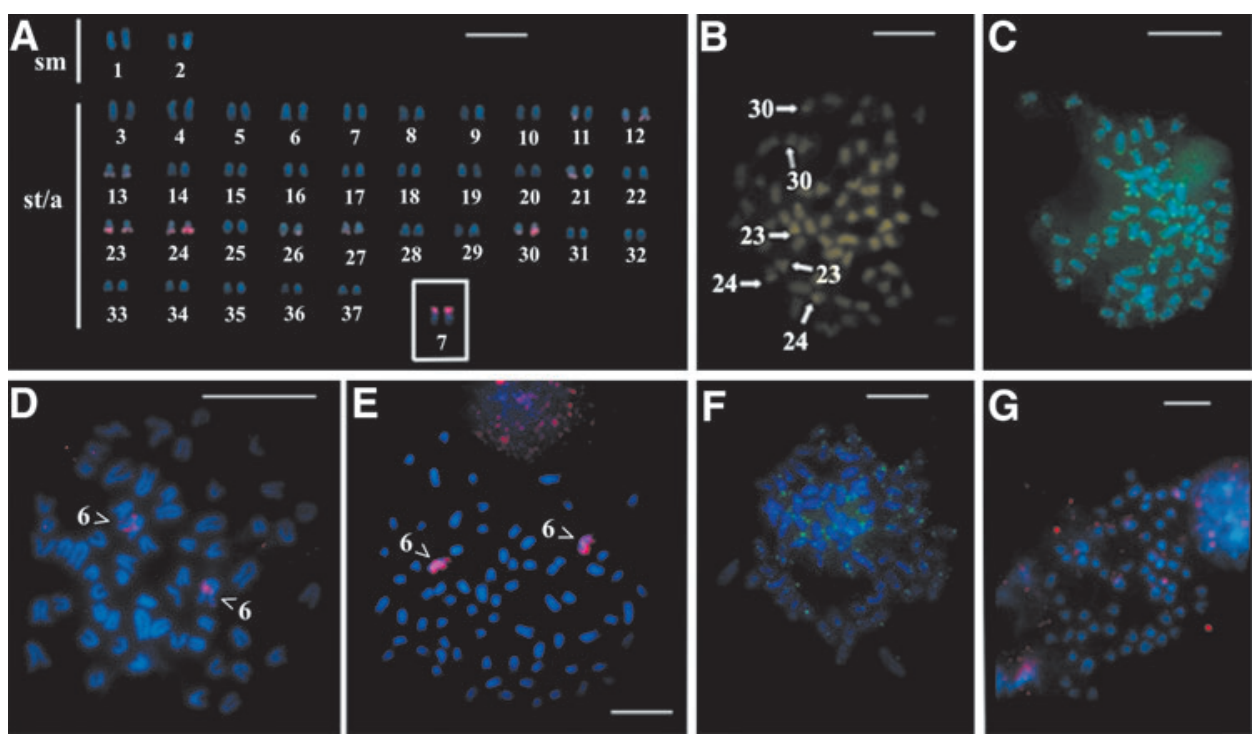

(Fig. 5A). FISH with 5S rDNA probe mapped this sequence in pericentromeric region of pair 7 (Fig. 5A, square).

The probe (TTAGGG)n detected the terminal sites in all chromosome complement with different signal intensities, and no ITS were detected (Fig. 5C). Probes for histones H1 and $\mathrm{H} 3$ revealed an interstitial signal on chromosome pair 6 (Fig. 5D and E, respectively). FISH with $\operatorname{Rex} 1$ and $\operatorname{Rex3}$ probes shows the presence of these repetitive elements on some heterochromatic regions (Fig. 5F and G, respectively).

\section{Discussion}

$R$. troscheli $(2 \mathrm{n}=54 ; \mathrm{FN}=66)$ shares the higher $2 \mathrm{n}$ already described for Gymnotiformes such as G. inaequilabiatus, ${ }^{9}$ G. carapo,${ }^{9}$ G. mamiraua,${ }^{10}$ and G. paraguensis. ${ }^{11}$ However, we herein report a new highest $2 \mathrm{n}$ for this family, which we found in $R$. cf eastwardi $(2 \mathrm{n}=74 ; \mathrm{FN}=78)$. This expands the karyotypic diversity known for this group of fish and suggests more complex karyotypic evolution for Gymnontiformes.

Among the Sternopygidae, the karyotypes of the diversified species of Eigenmannia $(2 \mathrm{n}=28-38 ; \mathrm{FN}=42-50)$ and a conserved $S$. macrurus $(2 \mathrm{n}=46 ; \mathrm{FN}=92)$ have relatively low diploid numbers compared with $R$. troscheli $(2 \mathrm{n}=54 ; \mathrm{FN}=66)$ and $R$. cf eastwardi $(2 \mathrm{n}=74 ; \mathrm{FN}=78)$. The former group, however, have higher FNs. This is due to the presence of more biarmed chromosomes, especially in $S$. macrurus $(2 \mathrm{n}=46, \mathrm{FN}=92)$, which has only biarmed chromosomes. $^{12,13}$ The karyotypic formulae of the studied Rhabdolichops species resemble those found in most species of Eigenmannia, especially, those with higher diploid numbers. ${ }^{7}, 13,14$ However, they are quite different from the published karyotypes of Sternopygus species, which only have biarmed chromosomes. ${ }^{12,13}$

The high diploid number found in Rhabdolichops suggests that chromosome fission may have contributed to the chromosomal evolution of this genus. Given the absence of interstitial telomeric signals in Rhabdolichops, we speculate that pericentric inversions and/or short arm additions could account for the increases in FN. Another possibility is that centromeric repositioning could be acting to promote the observed differences. ${ }^{29}$ The phylogenetic relationship of the
Sternopygidae $^{2}$ suggests that increases in diploid number could be a synapomorphic characteristic of genus Rhabdolichops among the Sternopygidae.

A high degree of AT-rich heterochromatin, such as observed in this study for Rhabdolichops, has been commonly observed among Sternopygidae; for example, it was previously described in $S$. macrurus ${ }^{13}$ and for several Eigenmannia species. ${ }^{7,16,18}$

A single NOR is the most common situation among the Sternopygidae, as confirmed by physical mapping of these genes in species of Eigenmannia. ${ }^{7,13,16,18}$ Consistent with this, we found only a single NOR in each of the studied species: on pair 6 of $R$. troscheli (Figs. 2 and 3) and on pair 30 of $R$. cf eastwardi (Figs. 4 and 5). The additional positive 18S rDNA clusters observed through FISH mapping in $R$. cf eastwardi are presumed not to reflect active NOR. Although a $5 \mathrm{~S}$ rDNA probe reportedly hybridized to multiple locations among $\mathrm{Ei}$ genmannia species, ${ }^{14}$ our 5S rDNA probe yielded only one signal in each of the tested species of Rhabdolichops.

The presence of major and minor ribosomal genes at multiple locations may reflect several kinds of chromosomal rearrangement, while the distal locations of the signals for $18 \mathrm{~S}$ rDNA (at the telomeres) and 5S rDNA (near the centromeres of acrocentric chromosomes) may suggest that Rabl orientation-associated factors have been involved in the spread of these ribosomal genes. In $R$. cf eastwardi, only three of the nine 18S rDNA genes were found to be associated with $\mathrm{CMA}_{3}$-positive $\mathrm{CG}$-rich regions (chromosome pairs 23, 24, and 30) (Fig. 5A, B). This is a relevant result since it is commonly accepted that $18 \mathrm{~S}$ rDNA genes are associated to GC-rich heterochromatin in fish. Our findings could indicate that these six 18S rDNA sites are so recent that heterochromatin has not yet had time to accumulate.

Also, Gromich et al. ${ }^{30}$ found out by sequenced FISH/banding in fishes that "not just some other regions besides NORs were stained with CMA3 and Ag, but also the majority of the $28 \mathrm{~S}$ rDNA sites were not detected," meaning that it is always important to check the classical and molecular cytogenetics data.

In recent years, sequence data and physical mapping have shown that several retrotransposons can be used as important markers for karyotypic comparisons. ${ }^{31,32}$ The Rex 
retroelements are widespread among the genomes of different fish lineages, and they have been mapped by in situ hybridization in numerous fish. ${ }^{33,34}$ The distribution patterns observed for the Rex retroelements have been found to vary across different groups: they are compartmentalized in pericentromeric heterochromatic regions among Cichlidae, Prochilodontidae, and Tetraodontidae ${ }^{35-37}$; they colocalize with ribosomal genes in some Cichlidae, Erythrinidae, and Loricariidae species ${ }^{38-40}$; they are associated with sexual heterochromatin in Channichthyidae ${ }^{41}$ and Anostomidae ${ }^{33}$; and they are dispersed throughout the genome in many species of Erythrinidae, Artedidraconidae, Bathydraconidae, Bovichtidae, Nototheniidae, and Loricariidae. ${ }^{32,39,41}$

The previous pattern was observed herein for the two studied species of Rhabdolichops (Sternopygidae). This pattern compartmentalized in pericentromeric heterochromatic regions is consistent with the idea that these transposons move and insert themselves along the genome.

Finally, we herein report the first mapping of two histone (H1 and H3) genes in members of Sternopygidae. As in other fish species, these genes appear to be clustered, ${ }^{42-46}$ and we observed their signals in the interstitial region of pair 6 for $R$. cf eastwardi (Fig. 5D, E), but were unable to physically map these genes in $R$. troscheli.

Our comparison between the karyotypes of $R$. troscheli and $R$. cf eastwardi show that, despite they can be found in the same geographic region and share some traits (a single active $18 \mathrm{~S}$ rDNA site, a single $5 \mathrm{~S}$ rDNA location, no ITSs, most of $\mathrm{CH}$ rich in AT pb and centromerically located, a heterochromatic pattern of Rex 1 and Rex 3 distribution), their karyotypes are quite different. $R$. troscheli has a more conserved karyotype when compared to other Gymnotiformes, while $R$. cf eastwardi shows a more divergent one, with higher diploid number, additional CG-rich distal $\mathrm{CH}$, apparently new NOR sites. This is even more evident if we take into account that $R$. troscheli and $R$. cf eastwardi are phylogenetically close species. ${ }^{47}$ All in all, our results strongly suggest that $R$. cf eastwardi experencied recent intense genome reorganization.

In the future, extending these observations to other Rhabdolichops species could help us identify the chromosomal rearrangements involved in the chromosomal evolution of this genus, potentially improving our understanding of the phylogenetic relationship among Rhabdolichops species.

\section{Acknowledgments}

This research was supported by Conselho Nacional de Desenvolvimento Científico e Tecnológico (CNPq) through the Edital Universal (proc. 475013/2012-3) and Coordenação de Aperfeiçoamento de Pessoal de Nível Superior (CAPES) through the Edital 047/2012 Pró-Amazônia: Biodiversidade e Sustentabilidade on a project coordinated by C.Y.N.; by FAPESPA (Pará Foundation for Supporting Science) through the National Excellence in Research Program (PRONEX, TO 011/2008) and Banco Nacional de Desenvolvimento Economico e Social (BNDES; Operação 2.318.698.0001) on a project coordinated by J.C.P. CYN (308428/2013-7) and J.C.P. (308401/2013-1) are grateful to CNPq for Productivity Scholarships. We thank the Instituto Chico Mendes de Conservação da Biodiversidade (ICMBio) for the collection permit 020/2005 (registration: 207419).

\section{Disclosure Statement}

No competing financial interests exist.

\section{References}

1. Albert JS, Crampton WGR: Diversity and phylogeny of Neotropical electric fish. In: Electroreception Springer Handbook of Auditory Research, vol. 21. Bullock TH, Hophins CD, Popper AN, and Fay RR (eds), pp. 306-408, Springer, New York, NY, 2005.

2. Tagliacollo VA, Bernt MJ, Craig JM, Oliveira C, Albert JS. Model-based total evidence phylogeny of Neotropical electric knifefishes (Teleostei, Gymnotiformes). Mol Phylogenet Evol 2016;95:20-33.

3. Lundberg JG, Mago-Leccia F. A review of Rhabdolichops (Gymnotiformes, Sternopygidae), a genus of South American freshwater fishes, with description of four new species. Proc Acad Nat Sci Philadelphia 1986;138:53-85.

4. Crampton WGR. Effects of anoxia on the distribution, respiratory strategies and electric signal diversity of Gymnotiformes fish. J Fish Biol 1998;53:307-330.

5. Crampton WGR: An ecological perspective on diversity and distributions. In: Historical Biogeography of Neotropical Freshwater Fishes. Albert JS and Reis RE (eds), pp. 165189, University of California Press, Berkeley, CA, 2011.

6. Milhomem SSR, Crampton WGR, Pieczarka C, Silva DS, Cardoso AL, Silva PC, et al. Chromosomal and electric signal diversity in three sympatric electric knifefish species (Gymnotus, Gymnotidae) from the Central Amazon Floodplain. Rev Fish Biol Fish 2011;22:1-13.

7. Silva DS, Peixoto LAW, Pieczarka JC, Wosiacki WB, Ready JS, Nagamachi CY. Karyotypic and morphological divergence between two cryptic species of Eigenmannia in the Amazon basin with a new occurrence of XX/XY sex chromosomes (Gymnotiformes: Sternopygidae). Neotrop Ichthyol 2015;13:297-308.

8. Mendes VP, Portela-Castro ALB, Ferreira Júlio-Júnior H. First record of supernumerary (B) chromosomes in electric fish (Gymnotiformes) and the karyotype structure of three species of the same order from the upper Paraná River basin. Comp Cytogenet 2012;6:1-16.

9. Scacchetti PC, Pansonato-Alves JC, Utsunomia R, Oliveira C, Foresti F. Karyotypic diversity in four species of the genus Gymnotus Linnaeus, 1758 (Teleostei, Gymnotiformes, Gymnotidae): physical mapping of ribosomal genes and telomeric sequences. Comp Cytogenet 2011;5: 223-235.

10. Milhomem SSR, Crampton WGR, Pieczarka JC, Silva DS, Cardoso AL, Silva PC, et al. Chromosomal and electric signal diversity in three sympatric electric knifefish species (Gymnotus, Gymnotidae) from the Central Amazon floodplain. Rev Fish Biol Fish 2012;22:485-497.

11. Margarido VP, Bellafronte E, Moreira-Filho O. Cytogenetic analysis of three sympatric Gymnotus (Gymnotiformes, Gymnotidae) species verifies invasive species in the Upper Paraná River basin, Brazil. J Fish Biol 2007;70:155-164.

12. Almeida-Toledo LF, Foresti F, Daniel MF, Toledo-Filho SA. Nucleolar chromosome variants in Sternopygus macrurus (Pisces, Sternopygidae) from three Brazilian river basins. Caryologia 1993;46:53-61.

13. Silva DS, Milhomem SSR, Souza ACP, Pieczarka JC, Nagamachi CY. A conserved karyotype of Sternopygus macrurus (Sternopygidae, Gymnotyformes) in the Amazon 
region: differences from other hydrographic basins suggest cryptic speciation. Micron 2008;39:1251-1254.

14. Sene VF, Pansonato-Alves JC, Utsunomia R, Oliveira C, Foresti F. Karyotype diversity and patterns of chromosomal evolution in Eigenmannia (Teleostei, Gymnotiformes, Sternopygidae). Comp Cytogenet 2014;8:301-311

15. Silva DS, Milhomem SSR, Pieczarka JC, Nagamachi CY. Cytogenetic studies in Eigenmannia virescens (Sternopygidae, Gymnotiformes) and new inferences on the origin of sex chromosomes in the Eigenmannia genus. BMC Genet 2009;10:74-82.

16. Fernandes CA, Bailly D, Silva VFB, Martins-Santos IC. System of multiple sex chromosomes in Eigenmannia trilineata López \& Castello, 1966 (Sternopygidae, Gymnotiformes) from Iguatemi River Basin, MS, Brazil. Cytologia 2010;75:463-466.

17. Sene VF, Pansonato-Alves JC, Ferreira DC, Utsunomia R, Oliveira C, Foresti F. Mapping of the retrotransposable elements Rex 1 and Rex 3 in chromosomes of Eigenmannia (Teleostei, Gymnotiformes, Sternopygidae). Cytogenet Genome Res 2015;146:319-324.

18. Bertollo LAC, Takashi CS, Moreira-Filho O. Cytotaxonomic considerations on Hoplias lacerdae (Pisces, Erythrinidae). Braz J Genet 1978;2:103-120.

19. Sumner AT. A simple technique for demonstrating centromeric heterochromatin. Exp Cell Res 1972;75:304-306.

20. Howell WM, Black DA. Controlled silver staining of nucleolus organizer regions with a protective colloidal developer: a 1-step method. Experientia 1980;36:1014-1015.

21. Schweizer D, Ambros PF. Chromosome banding. Stain combinations for specific regions. Methods Mol Biol 1994; 29:97-112.

22. Pinkel D, Straume T, Gray JW. Cytogenetic analysis using quantitative, high-sensitivity, fluorescence hybridization. Proc Natl Acad Sci U S A 1986;83:2934-2938.

23. Levan A, Fredga K, Sandberg AA. Nomenclature for centromeric position on chromosomes. Hereditas 1964;52:201-220.

24. Hatanaka T, Galetti PM Jr. Mapping $18 \mathrm{~S}$ and $5 \mathrm{~S}$ ribosomal RNA genes in the fish Prochilodus argenteus Agassiz, 1929 (Characiformes, Prochilodontidae). Genetica 2004;122: 239-244.

25. Ijdo JW, Wells RA, Baldini A, Reeders ST. Improved telomere detection using a telomere repeat probe (TTAGGG)n generated by PCR. Nucleic Acids Res 1991;19:4780.

26. Volff JN, Körting C, Schartl M. Multiple lineages of the non-LTR retrotransposon Rex 1 with varying success in invading fish genomes. Mol Biol Evol 2000;17:1673-1684.

27. Volff JN, Körting C, Sweeney K, Schartl M. The non-LTR retrotransposon Rex3 from the fish Xiphophorus is widespread among teleosts. Mol Biol Evol 1999;16:1427-1438.

28. Cabral-de-Mello DC, Moura RC, Martins C. Chromosomal mapping of repetitive DNAs in the beetle Dichotomius geminatus provides the first evidence for an association of $5 \mathrm{~S}$ rRNA and histone $\mathrm{H} 3$ genes in insects, and repetitive DNA similarity between the B chromosome and A complement. Heredity 2010;104:393-400.

29. Rocchi M, Archidiacono N, Schempp W, Capozzi O, Stanyon R. Centromere repositioning in mammals. Heredity 2012;108:59-67.

30. Gromich M, Ozouf-Costaz C, Collares-Pereira MJ. Lack of correspondence between CMA3-, Ag-positive signals and $28 \mathrm{~S}$ rDNA loci in two Iberian minnows (Teleostei, Cypri- nidae) evidenced by sequential banding. Cytogenet Genome Res 2005;109:507-511.

31. Vicari MR, Nogaroto V, Noleto RB, Cestari MM, Cioffi MB, Almeida MC, et al. Satellite DNA and chromosomes in Neotropical fishes: methods, applications and perspectives. J Fish Biol 2010;76:1094-1116.

32. Ferreira DC, Oliveira C, Foresti F. Chromosome mapping of retrotransposable elements $\operatorname{Rex} 1$ and $\operatorname{Rex3}$ in three fish species in the Subfamily Hypoptopomatinae (Teleostei, Siluriformes, Loricariidae). Cytogenet Genome Res 2011;132: 64-70.

33. Borba RS, Silva EL, Parise-Maltempi PP. Chromosome mapping of retrotransposable elements Rex 1 and Rex3 in Leporinus Spix, 1829 species (Characiformes: Anostomidae) and its relationships among heterochromatic segments and W sex chromosome. Mob Genet Elements 2013;3: e27460.

34. Schneider CH, Gross MC, Terencio ML, Do Carmo EJ, Martins C, Feldberg E. Evolutionary dynamics of retrotransposable elements $\operatorname{Rex} 1, \operatorname{Rex} 3$ and $\operatorname{Rex} 6$ in neotropical cichlid genomes. BMC Evol Biol 2013;13:152.

35. Valente GT, Mazzuchelli J, Ferreira IA, Poletto AB, Fantinatti BEA, Martins C. Cytogenetic mapping of the retroelements Rex $1, \operatorname{Rex} 3$ and Rex6 among Cichlid fish: new insights on the chromosomal distribution of transposable elements. Cytogenet Genome Res 2011;133:34-42.

36. Teixeira WG, Ferreira IA, Cabral-de-Mello DC, Mazzuchelli J, Valente GT, et al. Organization of repeated DNA elements in the genome of the cichlid fish Cichla kelberi and its contributions to the knowledge of fish genomes. Cytogenet Genome Res 2009;125:224-234.

37. Voltolin TA, Mendonça BB, Ferreira DC, Senhorini JA, Foresti F, Porto-Foresti F. Chromosomal location of retrotransposable Rex 1 in the genomes in five Prochilodus (Teleostei: Characiformes: Prochilodontidae) species. Mob Genet Elements 2013;3:e25846.

38. Gross MC, Schneider CH, Valente GT, Porto JIR, Martins C, Feldberg E. Comparative cytogenetic analysis of the genus Symphysodon (Discus fishes, Cichlidae): chromosomal characteristics of retrotransposons and minor ribosomal DNA. Cytogenet Genome Res 2009;127:43-53.

39. Cioffi MB, Martins C, Bertollo LAC. Chromosome spreading of associated transposable elements and ribosomal DNA in the fish Erythrinus erythrinus. Implications for genome change and karyoevolution in fish. BMC Evol Biol 2010;10:271.

40. Pansonato-Alves JC, Serrano EA, Utsunomia R, Scacchetti PC, Oliveira C, Foresti F. Mapping five repetitive DNA classes in sympatric species of Hypostomus (Teleostei, Siluriformes, Loricariidae): analysis of chromosomal variability. Rev Fish Biol Fish 2013;23:477-489.

41. Ozouf-Costaz C, Brandt J, Korting C, Pisano E, Bonillo C, Coutanceau JP, et al. Genome dynamics and chromosomal localization of the non-LTR retrotransposons Rex 1 and Rex3 in Antarctic fish. Antarct Sci 2004;16:51-57.

42. Pendás AM, Morán P, García-Vázquez E. Organization and chromosomal location of the major histone cluster in brown trout, Atlantic salmon and rainbow trout. Chromosoma 1994;103:147-152.

43. Hashimoto DT, Ferguson-Smith MA, Rens W, Prado FD, Foresti F, Porto-Foresti F. Cytogenetic mapping of H1 histone and ribosomal RNA genes in hybrids between 
catfish species Pseudoplatystoma corruscans and Pseudoplatystoma reticulatum. Cytogenet Genome Res 2013; 139:102-106.

44. Silva DMZ, Pansonato-Alves JC, Utsunomia R, ArayaJaime C, Ruiz-Ruano FJ, et al. Delimiting the origin of a B chromosome by FISH mapping, chromosome painting and DNA sequence analysis in Astyanax paranae (Teleostei, Characiformes). PLoS One 2014;9:e94896.

45. Utsunomia R, Pansonato-Alves JC, Scacchetti PC, Oliveira C, Foresti F. Scattered organization of the histone multigene family and transposable elements in Synbranchus. Genet Mol Biol 2014;37:30-36.

46. Piscor D, Parise-Maltempi PP. Chromosomal mapping of H3 histone and 5S rRNA genes in eight species of Astyanax (Pisces, Characiformes) with different diploid numbers: syntenic conservation of repetitive genes. Genome 2016;59: 167-172.
47. Correa SB, Crampton WGR, Albert JS. Three new species of the Neotropical electric fish Rhabdolichops (Gymnotiformes: Sternopygidae) from the Central Amazon, with a new diagnosis of the genus. Copeia 2006;1:27-42.

Address correspondence to: Cleusa Yoshiko Nagamachi, PhD

Laboratório de Citogenética Centro de Estudos Avançados da Biodiversidade Instituto de Ciências Biológicas Universidade Federal do Pará Rua Augusto Corrêa, 01 Belém 66075-110

Brazil

E-mail: cleusanagamachi@gmail.com 